
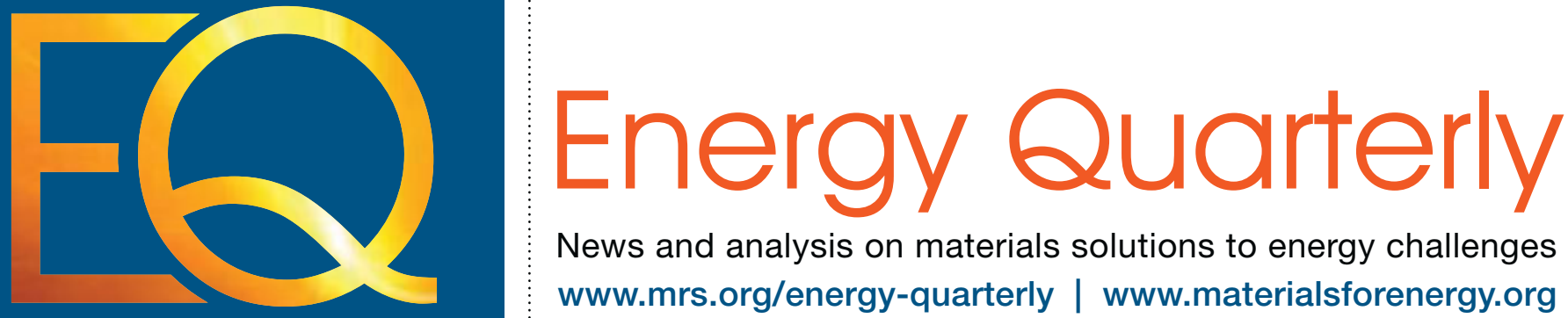

News and analysis on materials solutions to energy challenges www.mrs.org/energy-quarterly | www.materialsforenergy.org

Inside:

EDITORIAL

The tortoise and the hare

ENERGY SECTOR ANALYSIS

A capacity for change

\title{
INTERVIEW
}

The materials that make

an energy company:

BP chief scientist

Ellen Williams discusses

sustainable energy

\section{REGIONAL INITIATIVE}

Grid battery storage gets big in the States

\section{ENERGY FOCUS}

\section{ENERGY QUARTERLY ORGANIZERS}

CHAIR David Cahen, Weizmann Institute, Israel

Anshu Bharadwaj, Center for Study of Science,

Technology and Policy, India

Russell R. Chianelli, University of Texas, El Paso, USA

George Crabtree, Argonne National Laboratory, USA

Anke Weidenkaff, Empa, Swiss Federal Laboratories

for Materials Science and Technology and University

of Bern, Switzerland

M. Stanley Whittingham, State University of New York at Binghamton, USA

Steve M. Yalisove, University of Michigan, USA

Masthead updated on December 18, 2012

Images incorporated to create the energy puzzle concept used under license from Shutterstock. com

Energy Sector Analysis image of supercapacitors

courtesy of Maxwell Technologies Inc.

To suggest ideas for Energy QUARTERLY,

to get involved, or for information

on sponsorship, send email to

materialsforenergy@mrs.org.

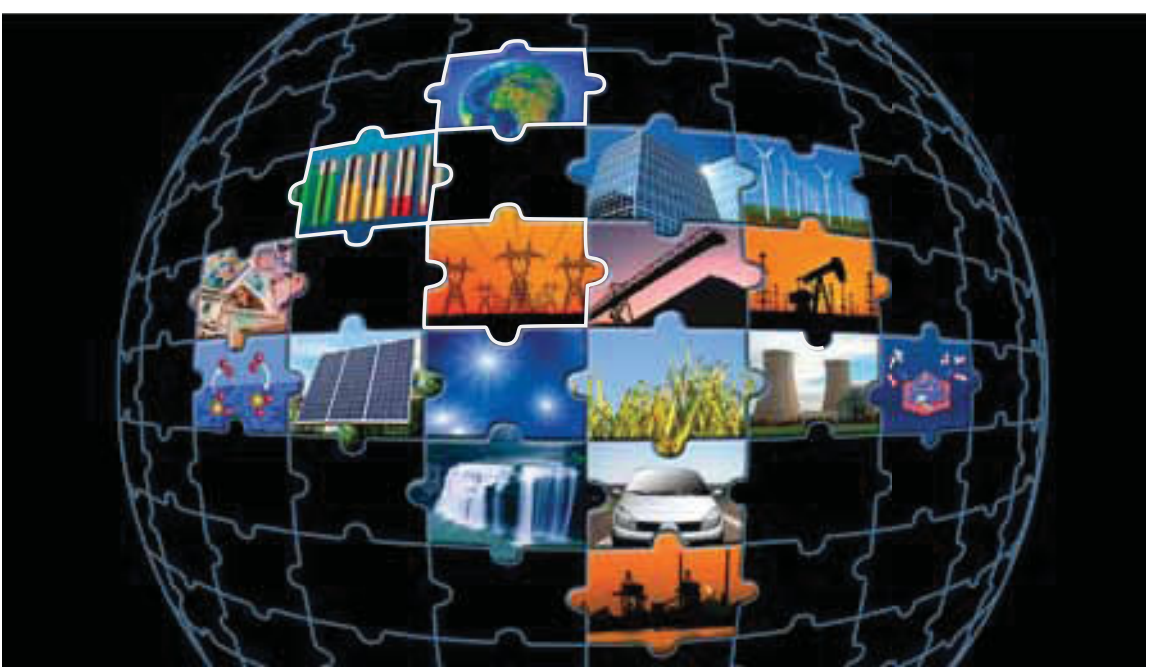

\section{The tortoise and the hare}

Batteries and supercapacitors fulfill different needs, the former for energy and the latter for power. They may be compared to the tortoise and the hare, respectively, the latter being able to go in short spurts whilst the former can keep going steadily for long distances. In an ideal situation, a combination of the two would work best. In vehicles, for example, the capacitors can take up energy on braking and release it for acceleration, with the batteries providing the main source of continuous power. This would relieve stress on the batteries, increasing their lifetime. In reality, major materials challenges make capacitors cost prohibitive for all but specialized applications. Wind and solar energy-generation would also be improved if a tortoise/hare combination were used, with the capacitors smoothing the output on a time scale of seconds, whereas the battery can provide the storage from a few minutes at the energy source (such as in facilities in Binghamton and West Virginia) to overnight, supplying power to the consumer.

Materials are a key limitation to more rapid and deeper deployment of large batteries and supercapacitors; lithium batteries already dominate the smaller size portable electronics market. Their cost, both the materials themselves and the manufacturing process, limit their use to specific niche markets. By their very nature, batteries (energy released in chemical reactions) and supercapacitors (energy released by surface discharge) are limited in the amount of storage. There is no long-term Moore's law; we will hit a limit. It is unrealistic to envisage a 300-mile personal vehicle being produced for the general public - chemistry simply is not going to allow it at a realistic price or in a viable volume or weight. The plug-in hybrid electric vehicle is almost certainly the path to the future, with most local commuting done on battery power, and the engine kicking in to regenerate the battery for longer trips. We as materials researchers must also be realistic and not over-hype the possibilities as has been happening with Li-air batteries, so that politicians and the general public do not become disenchanted and kill the goose that lays the golden eggs.

M. Stanley Whittingham 